\title{
Analysis of Power Loss Data for the 200 Area Tank Farms in Support of K Basin SAR Work
}

M. V. Shultz, Jr.

Date Published

December 1994

Prepared for the U.S. Department of Energy Office of Environmental Restoration and Waste Management

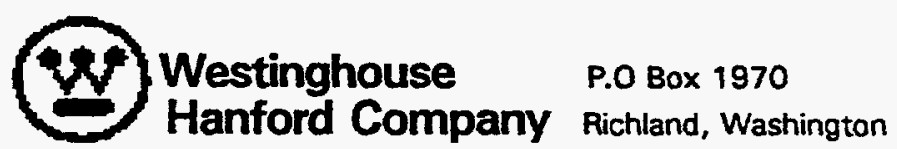

Henford Operations and Engineering Contractor for the

U.S. Department of Energy under Contract DE-AC06-87RL10930 


\section{DISCLAIMER}

This report was prepared as an account of work sponsored by an agency of the United States Government. Neither the United States Government nor any agency thereof, nor any of their employees, make any warranty, express or implied, or assumes any legal liability or responsibility for the accuracy, completeness, or usefulness of any information, apparatus, product, or process disclosed, or represents that its use would not infringe privately owned rights. Reference herein to any specific commercial product, process, or service by trade name, trademark, manufacturer, or otherwise does not necessarily constitute or imply its endorsement, recommendation, or favoring by the United States Government or any agency thereof. The views and opinions of authors expressed herein do not necessarily state or reflect those of the United States Government or any agency thereof. 


\section{RELEASE AUTHORIZATION}

Document Number: WHC-EP-0811

Document Title: - Analysis of Power Loss Data for the 200 Area Tank Farms in Support of K Basin SAR Work

Release Date: $\quad 2 / 8 / 95$

This document was reviewed following the procedures described in WHC-CM-3-4 and is:

APPROVED FOR PUBLIC RELEASE

WHC Information Release Administration Specialist:

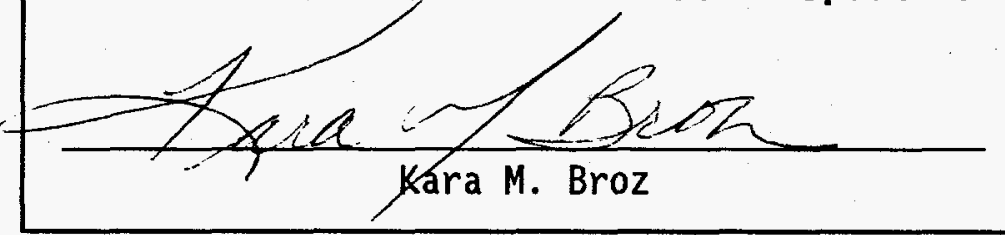

February 8, 1995 


\section{DISCLAMMER}

Portions of this document may be illegible in electronic image products. Images are produced from the best available original document. 
WHC-EP-0811.

Analysis of Power Loss Data for the 200 Area

Tank Farms in Support of $K$ Basin SAR Work

Prepared by:
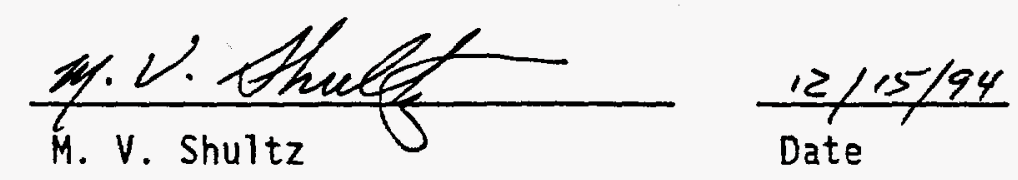

Reviewed by:

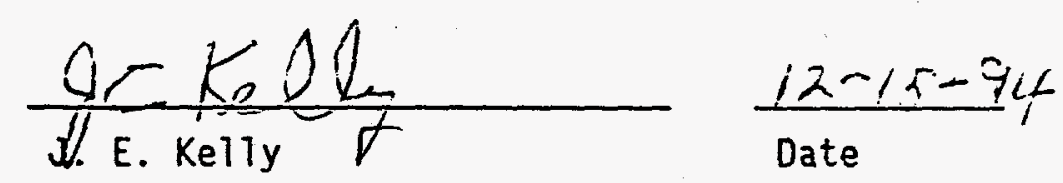

Approved by:

3. P. Hinckley

$\frac{12-15-94}{\text { Date }}$

ii 
WHC-EP-0811

\section{Contents}

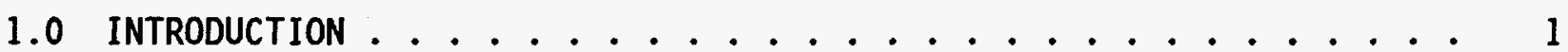

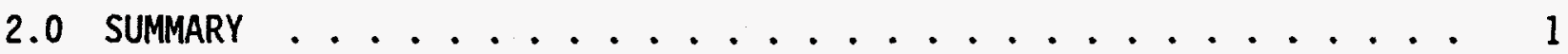

3.0 DISCUSSION OF ANALYSIS ................ 1

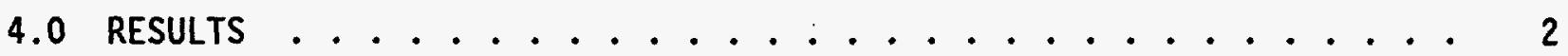

5.0 REFERENCES ......................... 4

APPENDIXES

A. SUMMARY OF 200 AREA POWER LOSS OCCURRENCE REPORTS . . . . . 7

B. 200 AREA POWER SUPPLY CONFIGURATION ............ 13

C. EXTREME VAlUE STATISTICS .................. 16

\section{List of Tables}

1. Power Loss Event Summary ................... 3

\section{List of Figures}

1. Extreme Value Plot for Outages of One Hour or Greater ....... 5

2. Extreme Value Plot for All Power Outage Data ......... 6 
WHC-EP-0811

\section{ANALYSIS OF POWER LOSS DATA FOR THE 200 AREA TANK FARMS IN SUPPORT OF $K$ BASIN SAR WORK}

\subsection{INTRODUCTION}

An analysis of power loss data for the 200 Area Tank Farms was performed in support of $K$ Basin safety analysis report work. The purpose of the analysis was to establish a relationship between the length of a power outage and its yearly frequency. This relationship can be used to determine whether the duration of a specific power loss is a risk concern. The information was developed from data contained in unusual occurrence reports (UORs) spanning a continuous period of 19.75 years.

\subsection{SUMMARY}

A review of Hanford Site UOR records covering the years 1972 to 1992 was used to identify events that resulted in loss of normal power to the 200 Area Tank Farms. An extreme value plot of 200 Area power loss data was generated from the information in the UORs to establish a relationship between power outage length and average yearly frequency of occurrence. The plot may be used to determine the yearly frequency of a given length outage or it may be used to determine the length of an outage related to a specified yearly frequency. Since the data used to develop this relationship is Hanford specific, its applicability is limited to Hanford Site concerns.

Use of this plot gives an average yearly frequency of $2.5 \times 10^{-1}$ for an outage of 1 hour, $6.7 \times 10^{-2}$ for an outage of 4 hours, $1.0 \times 10^{-2}$ for an outage of 24 hours, and $5.0 \times 10^{-3}$ for an outage of 48 hours. All yearly frequencies are for risk exposures of one full year ( 8760 hours).

The average frequency of power loss calculated from the UOR information is 1.22 events per year. The mean of the power loss duration is 32.5 minutes and the median duration is 2 minutes. Nine events resulted in loss of power to both 200 East and 200 West areas simultaneously. Seven events (not necessarily the same events that resulted in loss of power to both 200 areas) resulted in outage durations exceeding 5 minutes. Approximately one-half of the events were caused by human error. The other half resulted from natural phenomena or equipment failures. None of the outages were reported to have any adverse effect on the tank farms.

\subsection{DISCUSSION OF ANALYSIS}

A review of Hanford Site UOR records covering the years 1972 to 1992 was used to identify events that resulted in loss of normal power to the 200 Area Tank Farms. These reports are used to communicate occurrence of significant off-normal events to the U.S. Department of Energy. Each report describes the event, conditions at the time of the event, and immediate and permanent corrective actions. 
The review identified 25 events from 24 UORs covering a period of 19.75 years that resulted in power loss to the tank farms. Of the 25 events, 18 had power loss durations of 5 minutes or less. The minimum length of outage was 0.1 minute, and the maximum was 251 minutes. The frequency of power loss is 1.22 events per year. The mean of the power loss duration is 32.5 minutes and the median duration is 2 minutes. Nine events resulted in simultaneous loss of power to both 200 East and 200 West areas. Seven events (not necessarily the same events that resulted in loss of power to both 200 areas) resulted in outage durations exceeding 5 minutes. Approximately one-half of the events were caused by human error. The other half resulted from natural phenomena or equipment failures.

The power loss events are described in Appendix $A$ and summarized in Table 1. A description of the 200 Area power supply is provided in Appendix $B$ for completeness. An abbreviated discussion of the statistical theory of extreme values is contained in Appendix C. Further detailed information on the theory and use of extreme value statistics can be found in reference 1 .

\subsection{RESULTS}

An extreme value plot of 200 Area power loss data was generated to establish a relationship between outage length and yearly frequency of occurrence. The extreme value plot is presented as Figure 1. The longest power loss for each year from 1972 to 1992 was used in the development of the plot. Figure 1 is the plot of outages of one-half hour or greater. The choice of a lower cutoff for power outage length was dictated by the indication of a significant change in character between outages of less than one-half hour and the longer outages.

Frequency per year is the inverse of the year value indicated on the return period scale at the top of the graph. The frequency of power loss of a specified duration can be determined by projecting from the intersection of the fitted straight line from outage length to the return period scale at the top of the graph. In a like manner, projection from the intersection with the straight line from return period to outage length will provide outage length from a given frequency. Picking values off the return period scale of Figure 1 should be limited to an accuracy of one-half division due to uncertainty in the fitting of a straight line to the data.

The differences in plot line slope for the two categories of outages may be the result of differences in the basic nature of the outage causes. Short duration outages appear to be caused by 1 imited localized conditions that are corrected by mechanical means, such as automatic or manual switch reclosure or feed rerouting recovery actions that can be implemented at the 251-W Substation. For outages of one-half hour or greater, the causes may not be localized in nature, and outage length is related to the extent of damage, availability of replacement material, or time required for a line crew to fix the problem in the field. The slope of the straight line fitting the data 
Table 1. Power Loss Event Summary.

\begin{tabular}{|c|c|c|c|c|}
\hline $\begin{array}{l}\text { Outage Length } \\
\text { (Minutes) }\end{array}$ & Outage Date & Area Affected & Report Number & Cause \\
\hline 2 & $6 / 15 / 72$ & $\begin{array}{l}\text { All Tank Farms coccurred } 7: 42 \text { p.m. on } \\
6 / 15 / 72)\end{array}$ & $72-37$ & Weather \\
\hline 2 & $6 / 15 / 72$ & $\begin{array}{l}\text { All Tank Farms (occurred 12:55 a.m. on } \\
6 / 16 / 72)\end{array}$ & $72-37$ & Weather \\
\hline 251 & $1 / 8 / 73$ & 200 West Area (Line $(8-L 4)$ & $73-1$ & Equip. Fail \\
\hline 35 & $4 / 18 / 74$ & 241-s Farm Only & $74-32$ & Human Error \\
\hline 2 & $3 / 1 / 75$ & Bus \#1 (241-A, 241-AX, and 241-AY) & $75-21$ & Equip. Fail \\
\hline 193 & $3 / 1 / 75$ & $\begin{array}{l}241-5 x \text { only (Initiated by failure } \\
\text { reported in } 75-21 \text { ) }\end{array}$ & $\pi-24$ & Equip. Fail \\
\hline 1 & $5 / 14 / 75$ & 241-A, 241-AX, and 241-AY & $75-59$ & Birds \\
\hline 0.1 & $11 / 2 / 76$ & All Tank Farms & $76-150$ & Human Error \\
\hline 0.17 & $7 / 26 / 77$ & All Tank Farms & $77-126$ & Equip. Fail \\
\hline 2 & $1 / 13 / 78$ & $\begin{array}{l}\text { Bus } \# 2 \text { (Most of tank farms in } 200 \text { East } \\
\text { and } 200 \text { West) }\end{array}$ & $78-7$ & Human Error \\
\hline 121 & $5 / 20 / 78$ & 241-TX (Dependant on Line Crew Arrival) & $78-51$ & Equip. Fail \\
\hline 75 & $4 / 17 / 79$ & All 200 East Area Tank Farms & $79-44$ & Equip. Fail \\
\hline 1.5 & $8 / 30 / 79$ & $241-\mathrm{A}, 241-\mathrm{AZ}, 241-\mathrm{BX}, 241-\mathrm{BY}, 241-\mathrm{C}$ & $79-84$ & Weather \\
\hline 21 & $9 / 1 / 79$ & $241-T X$ & $79-85$ & Weather \\
\hline 0.58 & $2 / 9 / 80$ & All Tank Farms & $80-19$ & Human Error \\
\hline 1 & $7 / 18 / 80$ & $\begin{array}{l}241-A N, 241-A P, 241-A H, 241-A Z, 241-B, \\
241-B X, 241-B Y, 241-C\end{array}$ & $80-67$ & Human Error \\
\hline 1 & $12 / 5 / 80$ & 241-A, 241-AZ, 241-BX, 241-BY, 241-C & $80-100$ & Human Error \\
\hline 1 & $7 / 6 / 83$ & $241-A, 241-A Z, 241-B X, 241-B Y, 241-C$ & $83-17$ & Weather \\
\hline 5 & $10 / 27 / 83$ & $\begin{array}{l}\text { 241-AN, 241-AP, 241-AH, 241-AZ, 241-B, } \\
241-\mathrm{BX}, 241-\mathrm{BY}, 241-\mathrm{C}\end{array}$ & $83-27$ & Human Error \\
\hline 5 & $3 / 26 / 85$ & 241-A, 241-AZ, 241-BX, 241-BY, 241-C & $85-29$ & Equip. Fail \\
\hline 1 & $3 / 27 / 85$ & All Tank Farms & $85-30$ & Equip. Fail \\
\hline 1 & $12 / 25 / 89$ & 200 West Tank Farms (Motor Burnout) & $89-65$ & Equip. Fail \\
\hline 1 & $12 / 25 / 89$ & $\begin{array}{l}200 \text { West Tank Farms (Attempt to } \\
\text { Reenergize Motor) }\end{array}$ & $89-65$ & Human Error \\
\hline 1 & $11 / 16 / 91$ & 200 Hest Tank Farms & $1991-1063$ & Weather \\
\hline $\begin{array}{r}30 \\
120\end{array}$ & $3 / 16 / 92$ & $\begin{array}{l}200 \text { West Tank Farms } \\
200 \text { East Tank Farms }\end{array}$ & $1992-0028$ & $\begin{array}{l}\text { Equip. Fail } \\
\text { Equip. Fail }\end{array}$ \\
\hline
\end{tabular}


points of outages one-half hour or greater is chosen as the appropriately conservative relationship of the duration and frequency of power outages for the 200 Areas. Figure 2 shows the difference in slopes of a line fitted to data for short (less than one-half hour) outages compared to a line fitted to longer outage data. Data for all outage extreme values from 1972 to 1992 are plotted.

The data used in creating Figure 1 is actuarial. It does not, in fact cannot, reflect the effect of possible, but unlikely events that have not occurred. If care is not taken when using the yearly frequencies determined from Figure 1, erroneous conclusions can be made. One such erroneous conclusion would be that return periods for very long outages, such as 1000 hours, are entirely valid. Outage length is normally limited by the time required for repairs. Unless damage is so wide spread or repair resources completely unavailable there will be some maximum outage length that will not be exceeded. There may also be an upper bound for power outage length because there are innovative "abnormal" ways to get power to a specific area if the urgency of recovering power is great enough that necessary resources are brought to bear.

As indicated above, outages of great length would most likely be the result of catastrophic events that severely affect the ability to make repairs. The likelihood of that type of event may be higher or lower than the extreme value plot would indicate. The type of event that has this effect is considered a "common cause" concern because it affects several things that are considered unrelated under normal circumstances. Analysis to identify "common cause" initiating events or conditions should take place when long duration low frequency $\left(<10^{-3}\right.$ per year) power outages are of concern. Such events could be severe earthquakes, large floods, large scale extreme winds, very large and destructive range fires, or acts of sabotage. Careful examination of the effects and frequency of these types of events should be made to verify the appropriateness of the frequency of a long-length outage.

The shortest power outage in the data was 0.1 minute. The longest was 251 minutes. The average frequency of power loss is 1.22 events per year. The mean of the power loss duration is 32.5 minutes. The median duration is 2 minutes. Nine events resulted in simultaneous loss of power to both 200 East and 200 West areas. Seven events (not necessarily the same events that resulted in loss of power to both areas) resulted in outage durations exceeding 5 minutes. Approximately one-half of the events were caused by human error. The other half were a result of natural phenomena or equipment failures. None of the outages were reported to have any adverse effect on the tank farms.

\subsection{REFERENCES}

1. National Bureau of Standards, 1954, "Statistical Theory of Extreme Values and Some Practical Applications by Emil J. Gumbel," A Series of Lectures by Emil J. Gumbel, National Bureau of Standards Applied Mathematics Series, Number 33, National Bureau of Standards, Washington, D.C. 


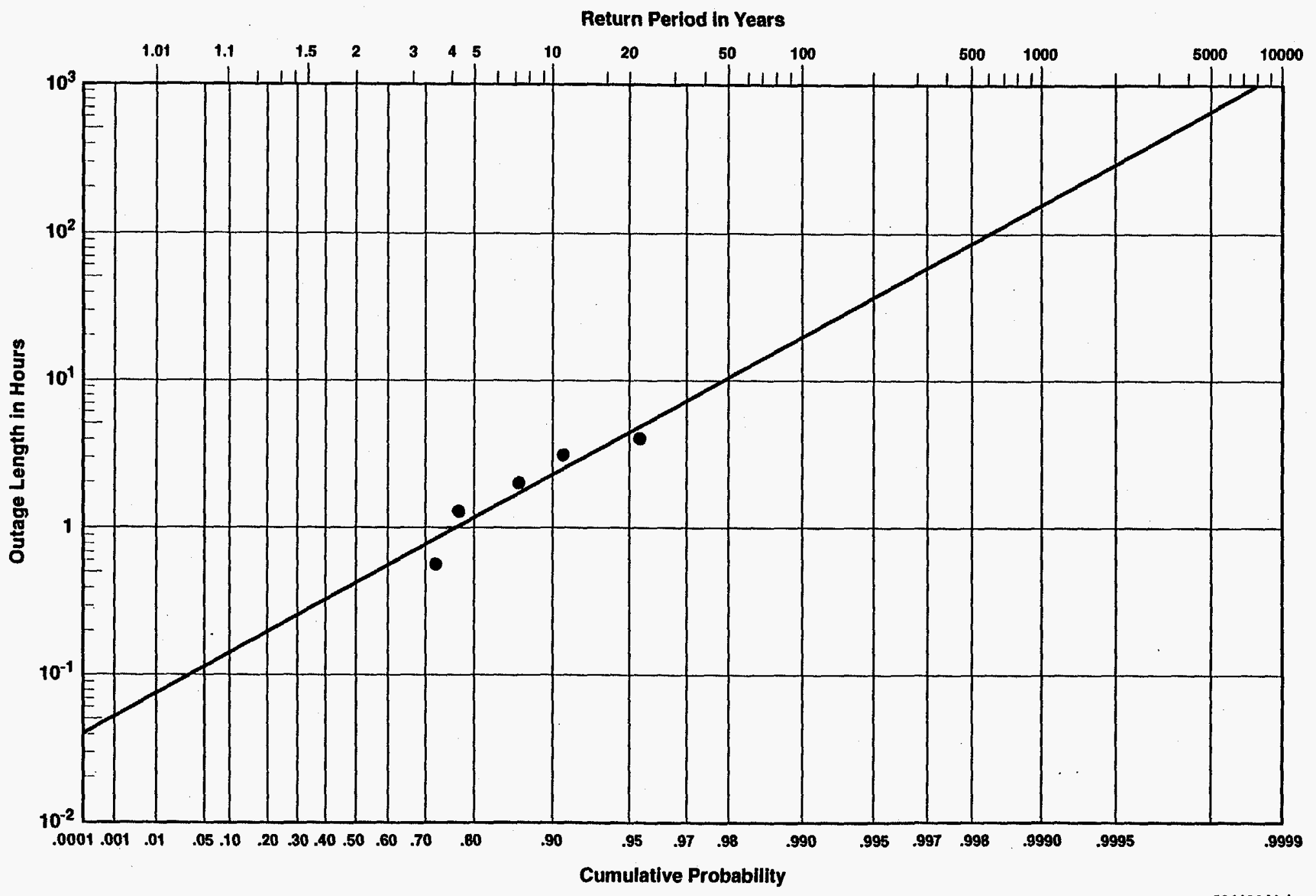

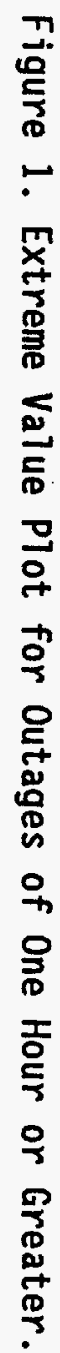

39412041.1 
Figure 2. Extreme Value Plot for A11 Power Outage Data.

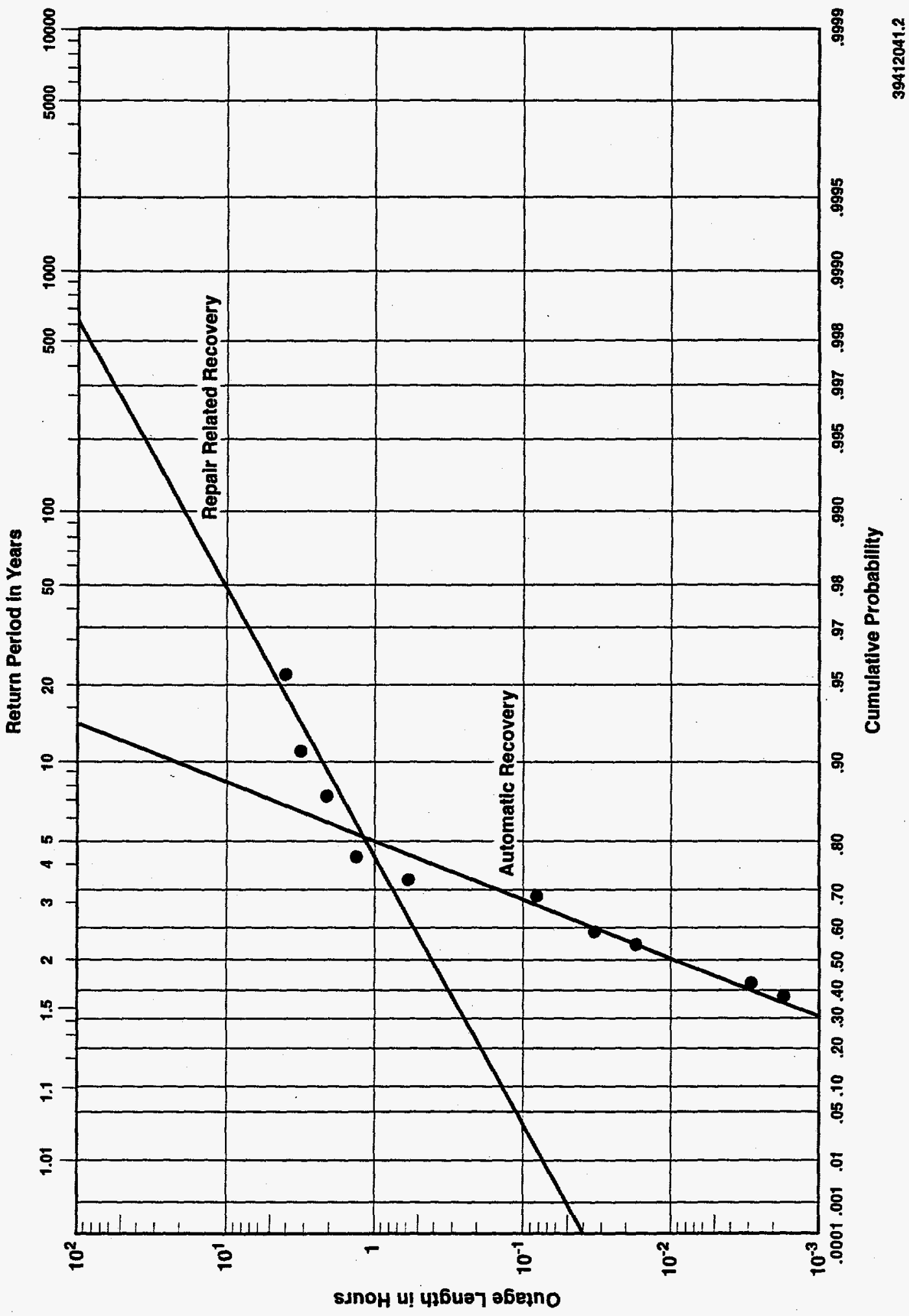


WHC-EP-0811

\section{APPENDIX A \\ SUMMARY OF 200 AREA POWER LOSS OCCURRENCE REPORTS}

1. Occurrence Report \#72-37

June 15,1972 and June 16,1972

Power outages in 200 and 300 areas due to electrical storm activity.

Lightning strikes caused outages of approximately two minutes in the 200 East and 200 West areas at 7:42 p.m. 6/15/72 and 12:55 a.m. 6/16/72. These outages would have affected the tank farms.

2. Occurrence Report \#73-1

January 8, 1973

200 West Area, 244-UR Tank Farm, 13.8-kV line failure, C8-L4

One phase of 13.8-kV line had broken and was found lying on the ground, still energized. It was discovered at 3:35 a.m., and the section was replaced and back in service 7:46 a.m. No effect on safety.

3. Occurrence Report \#74-32

April 18, 1974

200 West Area, 241-S Tank Farm

Test hole drilling resulted in damage to direct-buried cable supplying power to instruments in 241-S Tank Farm. Event occurred at 10:55 a.m. and power was restored at 11:30 a.m. to all but the 242-S building. Power was restored to $242-S$ at 6:34 p.m.

4. Occurrence Report \#75-21

March 1, 1975

200 East and 200 West areas fed by Bus 1 at 251-W Substation

A 13.8-kV single line to ground fault at 1:52 a.m. caused a bus 1 electrical outage. Lines C8-LI, C8-L3, C8-L5, and C8-L7 were affected. The power outage lasted approximately two minutes. Although exact electrical system configuration is not available for this time period, current electrical configuration would indicate that Tank Farms 241-A, 241-AX, and 241-AY were affected by this outage.

5. Occurrence Report \#75-24

March 1, 1975

200 West Area, REDOX 2400-V automatic switchgear

The event described in 0ccurrence Report 75-21 caused a demand for operation of the automatic switchgear at the REDOX Facility. The switchgear malfunctioned, causing an extended outage of normal power for REDOX, 222-S, and 241-SX Tank farm. Normal power was manually restored to those facilities at 5:05 a.m. Emergency power operated normally. 
6. Occurrence Report \#75-59

May 14, 1975

200 East Area, Line C8-L5 outage

Feeder breaker C8-X5 at 251-W Substation at 9:35 a.m. opened and reclosed 60 seconds later on normal reclosure action. Although exact electrical system configuration is not available for this time period, current electrical configuration would indicate that Tank Farms 241-A, 241-AX, and 241-AY were affected by this outage.

7. Occurrence Report \#75-150

November 2, 1976

200 East and 200 West areas, momentary outage

While working on a new relay installation at 251-W Substation, a Bonneville Power Administration (BPA) electrician inadvertently bumped a protective relay causing breaker A-386 to trip at 12:06 p.m. and reclose in six seconds. The 251-W Substation was in an abnormal configuration, and the breaker trip resulted in loss of all power to the 200 areas including all tank farms.

8. Occurrence Report \#77-126

July 261977

200 East and 200 West areas, Momentary outage

A fault on the 230-kV Hanford 100p resulted in a 200 Area power outage at 4:20 a.m. due to faulty directional ground relay action. The outage lasted approximately 10 seconds. A17 200 Area tank farms were affected.

9. Occurrence Report \#78-7

January 13, 1978

200 East and 200 West areas

An electrician inadvertently caused the trip of the 230-kV breaker A-384 and the $13.8-\mathrm{kV}$ breaker $\mathrm{C} 8 \times 200$ at $8: 58 \mathrm{a} . \mathrm{m}$. causing a two-minute power loss to bus 2 at the 251-W Substation. Lines C8-L2, C8-L4, C8-L6, and C8-L8 were affected. Although exact electrical system configuration is not available for this time period, current electrical configuration would indicate that Tank Farms 241-AN, 241-AP, 241-AW, 241-AZ, 241-B, 241-BX, 241-BY, 241-C, 241-S, 241-SX, 241-SY, 241-T, 241-TX, 241-TY, and 241- $U$ were affected by this outage. 
10. Occurrence Report \#78-51

May 20, 1978

200 West Area

A 13.8-kV electrical cable failed at $4: 13 \mathrm{p} . \mathrm{m}$. causing an outage on 1 ine C8-Ll feeding power to the 200 West Area. All interrupted loads were transferred to alternate 1ines. Power was restored to the 241-TX tank farm in 121 minutes. The amount of time to recover power to the 241-TX tank farm was dictated by the time of arrival of the line maintenance crew.

11. Occurrence Report \#79-44

Apri7 17, 1979

200 East and 200 West areas

The \#1 13.8-kV bus faulted and relayed out at 251-W Substation at $4: 24 \mathrm{a} . \mathrm{m}$. This interrupted power to lines $\mathrm{C} 8-\mathrm{L} 1, \mathrm{C} 8-\mathrm{L} 3, \mathrm{C} 8-\mathrm{L} 5$, and C8-L7. Although exact electrical system configuration is not available for this time period, an occurrence report from later in 1979 indicates that loss of lines $\mathrm{C} 8-\mathrm{L} 5$ and $\mathrm{C} 8-\mathrm{L} 7$ would cause power loss to Tank Farms 241-A, 241-AZ, 241-BX, 241-BY, and 241-C. Power was restored at 5:29 a.m. in the 200 West Area and at 5:39 a.m. in the 200 East Area.

12. Occurrence Report \#79-84

August 30, 1979

200 East Area

Breakers in the 251-W Substation feeding 1 ines C8-L5 and C8-L7 tripped open at $4: 24 \mathrm{p} . \mathrm{m}$. and closed within 90 seconds on automatic reclosure. Loss of 1 ines $C 8-\mathrm{L} 5$ and $C 8-L 7$ would cause power loss to Tank Farms 241-A, 241-AZ, 241-BX, 241-BY, and 241-C.

13. Occurrence Report \#79-85

September 1, 1979

200 West Area

Wind gusts caused individual phases of two 2.4-kV circuits to touch at 5:52 p.m. Breaker action de-energized both circuits causing loss of power to part of the 241-TX complex. Power was restored to normal at $6: 13$ p.m.

14. Occurrence Report \#80-19

February 9, 1980

200 East and 200 west areas

A fault on the 230-kV system at 151-D area resulted in a complete momentary power outage at 10:28 a.m. to the 200 areas. Power was restored to the 200 areas in approximately 35 seconds. The power loss affected all tank farms. 
15. Occurrence Report \#80-67

July 18,1980

200 East Area

A Terex scraper struck a power pole guy wire at $1: 15 \mathrm{p} . \mathrm{m}$. causing the outboard wires on the top yard arm to pul1 loose. An adjacent pole was broken off at a point just above the lower yard arm. The incident caused a momentary complete outage to 200 East Area and a partial outage to 200 West Area lasting approximately three minutes. Power was restored to 1 ine C8-L6 in one minute, 1 ine $\mathrm{C} 8-\mathrm{L} 8$ in one hour, and 1 ine C8-L7 in three hours. Although the exact electrical system configuration for this time period is not available, current electrical configuration would indicate that 1 ine C8-L6 feeds Tank Farms 241-AN, 241-AP, 241-AW, 241-AZ, 241-B, 241-BX, 241-BY, and 241-C.

16. Occurrence Report \#80-100

December 5, 1980

200 East and 200 West areas

While switching the 251-W Substation and 230-kV 10op back to normal, breaker A-382 inadvertently opened causing a partial power outage to the 200 East and 200 West areas on lines C8-L1, C8-L3, C8-L5, and C8-L7. Although the exact electrical system configuration for this time period is not available, an occurrence report from 1979 indicates that loss of 1 ines $\mathrm{C} 8-\mathrm{L} 5$ and $\mathrm{C} 8-\mathrm{L} 7$ would cause power loss to Tank Farms 241-A, 241-AZ, 241-BX, 241-BY, and 241-C.

17. Occurrence Report \#83-17

July 6,1983

200 East and 200 West areas

A lightning strike at $12: 36 \mathrm{p} . \mathrm{m}$. caused a one-minute loss of power to the \#1 buss at 251-W Substation. A partial power outage to the 200 East and 200 West areas resulted on lines C8-LI, C8-L3, C8-L5, and C8-L7. Although exact electrical system configuration is not available for this time period, an occurrence report from 1979 indicates that loss of lines C8-L5 and C8-L7 would cause power loss to Tank Farms 241-A, 241-AZ, 241-BX, 241-BY, and 241-C.

18. Occurrence Report \#83-27

October 27, 1983

200 East and 200 West areas

A three-phase fault occurred at 11:55 a.m. on 1ine C8-L6 causing a loss of bus \#2 at the 251-W Substation. Power was restored by closing the bus tie breaker. Length of outage was not specified but probably did not exceed five minutes. Current electric system configuration would cause tank farms 241-AN, 241-AP, 241-AW, 241-AZ, 241-B, 241-BX, 241-BY, and 241-C to loose power. 
19. Occurrence Report \#85-29

March 26, 1985

200 East and 200 West areas

A pole fire occurred on $\mathrm{C} 8-\mathrm{L} 3$ in the 200 West Area near $\mathrm{T}$ plant. The fault was cleared by relaying protection and automatically reclosed per design. Upon reclosing, feeder breaker $C 8 \times 3$ failed to operate in a timely manner causing the 251-W Substation 13.8-kV Bus \#1 feed breaker to open. UOR does not state how long the outage lasted, but normal operating practices would have re-energized Bus \#I within a couple of minutes.

20. Occurrence Report \#85-30

March 27, 1985

200 East and 200 West areas

The 200 Areas were operating on single power feed due to maintenance activities. The \#2 230-kV/13.8-kV transformer at 251-W Substation developed a problem and was de-energized resulting in a one-minute power loss to all 200 Areas.

21. Occurrence Report \#89-65-TF-09

December 25, 1989

200 East Area

A one-minute power loss occurred that affected tank farms 241-B, 241-BX, 241-BY, 241-C, 241-AZ, 241-AN, 241-AW, and 241-AP. The power loss was a result of a motor burnout at the 283-E building, which caused 1ine C8-L6 to trip and then reset.

On $12 / 25 / 89$ a second power loss also occurred that affected the same areas as the initial power loss. At the time of the incident tank farm personnel were still attempting to restart equipment that shut down as a result of the first incident. Electrical personnel found that the portable transformer located at 241-AN tank farm had failed. The report does not indicate the length of the second outage, but normal operating practices would have limited the outage to areas other than 241-AN to about the same length of time as the first power loss.

22. Occurrence Report \#RL--WHC-TANKFARM-1991-1063

November 16, 1991

200 West Area

At 16:54 electrical power was lost to the C8-L4 line to the 200 West tank farm facilities. As a consequence the ventilation serving the 241-SY tank farm was shutdown. This line also feeds 241-S, 241-SX, 241-T, 241-TX, 241-TY, and 241-U tank farms. Power was restored one minute later. Power loss was caused by severe weather in the area. 
23. Occurrence Report \#RL--WHC-TANKFARM-1992-0028

March 16, 1992

200 East and 200 West areas

At 11:30 al1 power was lost to the 200 East and 200 West area tank farm offices and facilities. The event was caused by a problem at the 251-W Substation. Power loss to the 200 West Area tank farms lasted approximately 30 minutes while power loss to the 200 East Area tank farm lasted two hours. 


\section{APPENDIX B \\ 200 AREA POWER SUPPLY CONFIGURATION}

Power is supplied to the 200 East and 200 West areas of the Hanford Site from the 251-W Substation. This substation is part of the Hanford 230-kV

10op, which includes the 100-B Area Substation, 100-KW Area Substation, 100-KE Substation, and 100-D Area Substation as well as part of the BPA Midway

Substation. The BPA Ashe Substation is also connected to the Hanford loop via the Ashe tap located on Gable mountain.

Power is supplied to the substation at the 230-kV level from the Hanford 230-kV loop and is reduced to 13.8-kV through two transformers for

distribution to the 200 areas. The power to the transformers is configured so that oil circuit breakers provide fault isolation between the transformers at the 230-kV level.

The 200 areas are supplied by multiple 13.8-kV power lines supported on wood poles. A degree of separation of power supply is accomplished by use of a dual bus arrangement at the 251-W Substation. The two 230-kV/13.8-kV transformers supply separate $13.8-\mathrm{kV}$ buses. Power to each of the 200 areas comes from the 13.8-kV buses on multiple lines. Figure B-l shows the arrangement.

The multiple power supply arrangement for the 200 areas provides a high degree of flexibility. If power is available to the 251-W Substation and one of the 13.8-kV buses is operational, a route to a specific facility can be established. Only in cases where a power supply problem exists locally to the facility would repowering the facility be in question. 
WHC-EP-0811

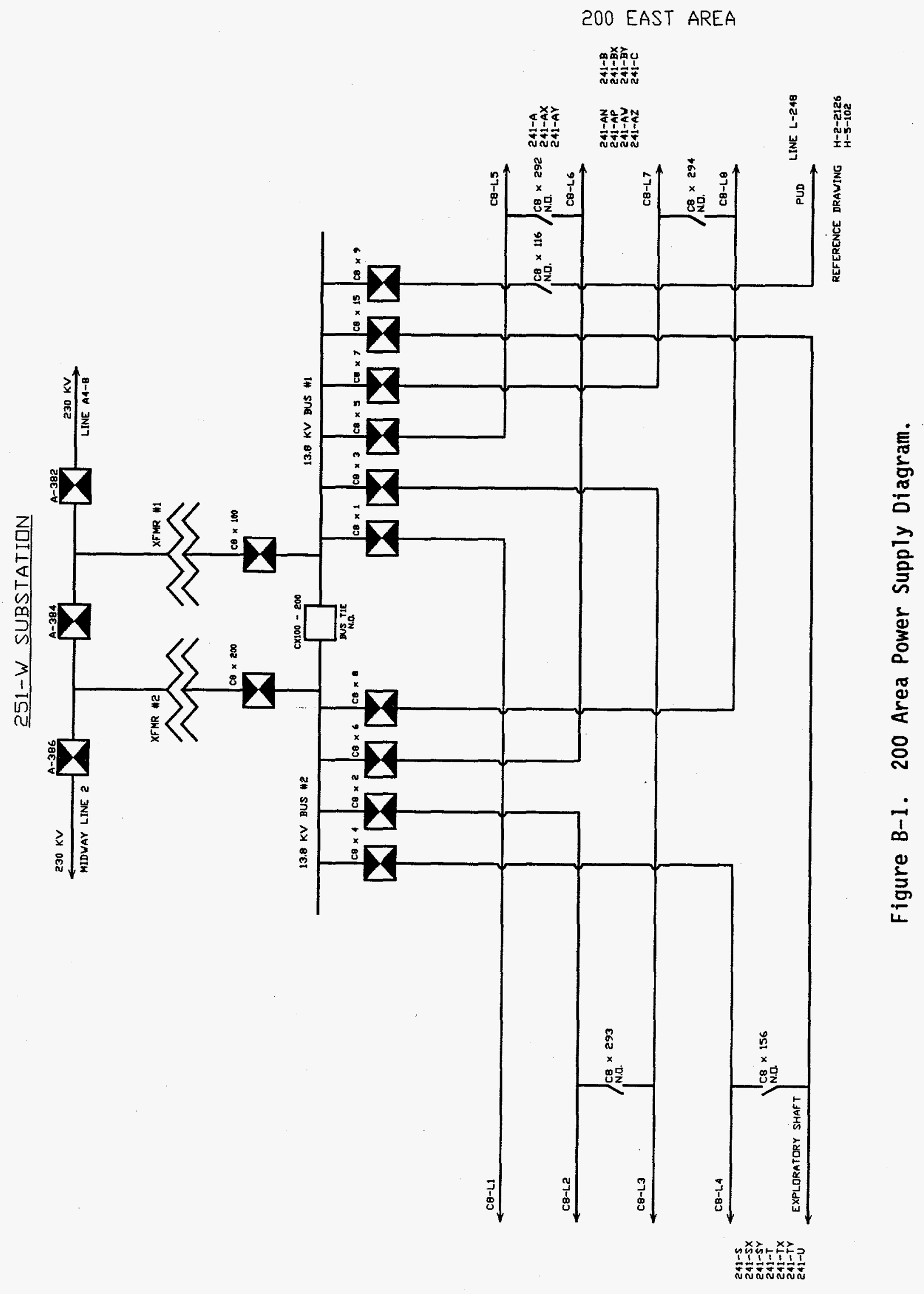


WHC-EP-0811

\section{APPENDIX C \\ EXTREME VALUE STATISTICS}

This appendix provides a limited discussion of extreme value statistics. A more complete discussion is contained in reference 1. The following material is derived from "Statistical Theory of Extreme Values and Some Practical Applications, A Series of Lectures by Emil J. Gumbel:"1

\section{C.1 INTRODUCTION ${ }^{2}$}

The first studies of extreme values arose, like many another statistical work, from the need of the astronomers to decide whether to accept or disregard an outlying observation that differs greatly from the rest.

The frequencies with which various volumes of discharges (river flow) are equalled or exceeded are important for determining the probability of damage, and for solving the problem of economic justification of flood control programs. These are also essential for analyzing the future operation of dams where appreciable volumes of runoff are to be stored temporarily, or in flood control studies where a reservoir is required to control a flood of specific frequency. The size of a dam, for example, is determined by the magnitude of flood that may be encountered and which must be withstood. We say that a certain height of flood level corresponds to a 100-year flood when, according to the data and the analysis thereof, such a flood or a larger one is likely to occur once in 100 years. On the other hand, it would seem impractical to protect against 10,000-year floods, even if the costs and engineering difficulties were not insurmountable obstacles. It is therefore of vital importance to have a simple practical method for estimating flood frequencies.

Similar stationary time series may easily be obtained for the annual largest precipitations, snowfalls, for the maxima and minima of atmosphere pressures and temperatures and other meteorological phenomena. Corresponding graphs may also be constructed for the largest earthquakes. In all these cases the year, being a natural unit of periodicity, automatically determines the number $n=365$ as the size of the sample from which the largest value is taken for analysis. Ordinarily, such a natural determination of sample size does not occur.

\section{C.2 MEANING OF THE RETURN PERIOD 3}

If a discontinuous variate is considered, such as the results of rolling a die, the probability that a certain side will be rolled is $1 / 6$. If this is an unbiased die, we may expect to get this side on the average, once in $T=6$ trials, given that a large number of trials are performed. In the case of a continuous variate, the probability for a certain value $x$ does not exist, only a density of probability. However, there is a probability $1-F(x)$ that a value will be equalled or exceeded by $x$. Its reciprocal

$$
T(x)=\frac{1}{1-F(x)}
$$


WHC-EP-0811

is termed the return period. It is the number of observations such that, on the average, there is one observation equalling or exceeding $x$. The return period increases with the variate. Every distribution function has a return period; every return period has a distribution function. It is important, however, to realize that it is incorrect to specify an arbitrary function and claim it to be a return period. In reality, the return period is subject to the boundary conditions imposed on the probability function $F(x)$.

If observations are made in constant intervals of time, the return period, representing a number of these observations, is also an interval, measured in the same units, which explains why the term "return period" is used. If breaking strength of materials is being tested, the observations are associated with different sizes rather than time intervais. In this case, the return period is a size.

\section{C.3 EXTREME VALUE DISTRIBUTION}

\section{C.3.1 Exact distributions ${ }^{4}$}

Let $F(x)$ be the probability that the value of the variate is less than a certain $x$, and let $f(x)=F^{\prime}(x)$ be the density of probability, henceforth called the initial distribution. Then the probability that $n$ independent observations all fall short of $x$ evidently is $F^{n}(X)$. This is the probability for $x$ to be the largest among $n$ independent observations. In other words, the probability $\Phi_{n}\left(x_{n}\right)$ that the largest value falls short of $x_{n}$ is

$$
\Phi_{n}\left(x_{n}\right)=F^{n}\left(x_{n}\right)
$$

and the derivative

$$
\phi_{n}\left(x_{n}\right)=n F^{n-1}\left(x_{n}\right) f\left(x_{n}\right)
$$

is the distribution of the largest among $n$ independent observations.

\section{C.3.2 Cumulative Distribution Function and Probability Density Function ${ }^{4}$}

There are two types of extreme value distributions, commonly referred to as Type I and Type II. These distributions are also sometimes referred to as the first and second asymptotic probability functions. In the data analysis being discussed in this document, a Type II distribution is used to characterize the data. The Type II distribution (referred to as a logarithmic extreme value distribution) is related to the Type I distribution in the save way that a logarithmic normal distribution is to the normal distribution. Another way of stating this is that the normalized unit variable for the log-extreme value distribution is obtained by a simple logarithmic transformation of the unit variable of the extreme value distribution. 
Type I Distribution

The Type I cumulative distribution function and the probability density function are:

$$
\Phi(x)=\int_{-\infty}^{y} e^{-e^{-y}}
$$

and

$$
\phi(x)=\alpha e^{-y-e^{-y}}
$$

under the conditions that:

$$
\begin{gathered}
-\infty<y<\infty \\
y=\alpha(x-\tilde{x})
\end{gathered}
$$

$y=$ the normalized unit variable, also called the reduced variate.

$x=$ the value of the random variable.

$\tilde{x}=$ the mode, the measure of central tendency for the extreme value distribution.

$\alpha$, when expressed as $1 / \alpha$, is the measure of dispersion, called the Gumble slope.

The Type I cumulative and probability density functions are developed from the following analysis of the first asymptotic distribution of the largest value for the exponential type.

The mode $\tilde{x}_{n}$ of the largest value is obtained as the solution of

$$
\frac{n-1}{F(x)} f(x)=-\frac{f^{\prime}(x)}{f(x)}
$$

If $x$ becomes very large, the density of probability $f(x)$ becomes very small, and the same holds for the probability $1-F(x)$ of a value surpassing $x$. If the variate is unlimited, the derivative $f^{\prime}(x)$ also converges toward zero. If it is legitimate from a certain value $x$ onward to apply l'Hôpital's rule and obtain the relation

$$
\frac{f(x)}{1-F(x)}--\frac{f^{\prime}(x)}{f(x)}
$$

(a condition which is not met by all distributions), the mode $\tilde{x}_{n}$ of the largest value converges toward the expected largest value

$$
\tilde{x}_{n} \rightarrow u_{n}
$$


If the same rule may be applied to the next derivatives, the Taylor expansion of the probability function in the neighborhood of $u_{n}$ converges toward

$$
F(x)=1-\frac{1}{n} e^{-\alpha_{n}\left(x-u_{n}\right)}
$$

where $\alpha_{n}$ and $u_{n}$ are the two extremal parameters discussed previously. Consequently, the asymptotic probability

$$
\Phi(x)=\underset{n=\infty}{\lim } \Phi_{n}(x)
$$

that $x$ is the largest among $n$ values, and the asymptotic frequency distribution

$$
\phi(x)=\Phi^{\prime}(x)
$$

become:

$$
\Phi(x)=e^{-e^{-y}} ; \phi(x)=\alpha e^{-y-\theta^{-y}},-\infty<y<\infty
$$

where

$$
y=\alpha_{n}\left(x-u_{n}\right) \quad\left(I^{\prime}\right)
$$

is called the reduced largest value. The index $n$ will be omitted if the sample size $n$ is fixed.

The parameter $u$ is simply an average of the distribution $\varphi(x)$, namely, the mode. The parameter $1 / \alpha$ is a measure of dispersion, which turns out to be 1.7 percent 1 arger than the mean deviation of the extreme variate. 


\section{Type II Distribution} are:

The Type II cumulative distribution function and the probability density function

$$
\mathrm{II}(z)=\int_{0}^{z} \exp -\left(v_{n} / z\right)^{k}
$$

and

$$
\pi(z)=-k(\tilde{z} / z)^{k-1} \exp -(\tilde{z} / z)^{k}
$$

under the conditions that:

$$
0<z<\infty
$$

$z=$ the value of the random variable.

$$
\tilde{z} \text { = the mode. }
$$

$k$, when expressed as $1 / k$, is the measure of dispersion, called the Geometric Gumbel Slope The Type II cumulative and probability density functions are developed from the following analys is of the second asymptotic distribution of the largest value.

An initial distribution of an unlimited variate $z$ unbounded to the right is said to be of the Cauchy type if (3.12) holds.

For large values of $z$ we may write approximately

$$
F(z)=1-A z^{-k}
$$

If the expected largest value $v_{n}$, defined for a sample of size ${ }_{n}$, is introduced, the initial probability function becomes

$$
F(z)=1-\frac{1}{n}\left(\frac{v_{n}}{z}\right)^{k}
$$

For large numbers $n$, the second asymptotic probability function of the large $t$ value II $(z)$ due to Fréchet, is

$$
\Pi(z)=\exp -\left(v_{n} / z\right)^{k}, \quad 0 \leq z \leq \infty
$$


The parameter $v_{n}$ increases with $n$, whereas $k$ is an order of moments and independent of $n$. The interesting cases are, of course, the small values $k=1,2,3$. The index $n$ may be omitted, if the sample size $n$ is fixed.

The first asymptotic distribution of the largest value is linked to the second one by the transformation

$$
\left(\frac{v}{z}\right)^{k}=e^{-\alpha(x-u)}
$$

Conversely, the asymptotic distribution of the Cauchy type is obtained from the asymptotic distribution of the exponential type by a logarithmic transformation.

\section{C.4 PROBABILITY PAPER ${ }^{3}$}

A very useful tool for the study of extreme values and breaking strength of materials is a very old instrument: probability paper. This gives a simple method of testing the fit between theory and observations, and without resorting to complex calculations. Therefore, the following discussion is provided to develop a scientific understanding of probability papers.

Let $x$ be a continuous variate, unlimited in both directions. Dimension such as length, time, etc., are not required to be an intrinsic part of the variate, although the variate may have them. Assume the existence of a linear reduction

$$
x=\mu+y / \alpha
$$

where $\mu$ and $1 / \alpha$ are parameters of the dimension $[x]$, and where $y$, called the reduced variate, has dimension zero. The parameter $\mu$ is a certain average, and $1 / \alpha$ a certain measure of dispersion.

A probability paper is a rectangular grid where the observed variate $x$ is plotted on one axis, and the reduced variate $y$ is plotted on the other axis. The probability function of the reduced variate

$$
\Phi(y)=F(x)
$$

is plotted on a scale parallel to the scale of $y$. If the distribution is symmetrical about zero, the probability $\Phi=\frac{1}{2}$ corresponds to $y=0$. The return period can be plotted on another scale parallel to the scale of $y$. The scales $x, y, F(x), T(x)$ constitute the complete scheme of a probability paper. The scales for $y$ and $x$ are both linear. The scales for $F(x)$ and $T(x)$ are not linear. If the choice of probability paper is correct, the observations plotted on this paper will fit a straight line. 
WHC-EP-0811

\section{C.5 DATA PLOTTING CONSIDERATIONS}

The following discussion is derived from Probabilitỹ Charts for Decision Making ${ }^{5}$.

Probability paper is a device which spaces the dimensions of a particular distribution so that plots of cumulative frequency data result in a straight line, provided the correct probability paper has been chosen. However, instead of using the observed cumulative percentage at a given value level, one uses what is known as a "cumulative percentage for plotting."

The cumulative percentage for plotting position differs from the conventional cumulative percentage. Let us suppose that the data consists of samples of 10 observations each. The value of the first observation to be plotted in a given sample of ten should have the same relationship to $0 \%$ as the tenth observation is to $100 \%$. Thus, on the average, it is desirable to have the first and last observations to be about equidistant from $0 \%$ and $100 \%$ respectively. Gumbe $1^{1}$ and Ferre $11^{6}$ resolve the problem of defining a cumulative percentage plotting position for each observation in a sample by adjusting the cumulative frequency. The adjustment is made by multiplying the cumulative frequency by $100 \% /(n+1)$, where $n$ is the sample size. Note that the denominator $(n+1)$, is obtained simply by adding 1 to the sample size. The adjusted value is referred to as a cumulative percentage plotting, to distinguish it from the conventional cumulative value.

After the points are plotted, examine them by eye or by using a transparent straightedge to se if a reasonably straight 1 ine has resulted. If so, then a 1 ine may be fitted to the data points by Ferrell's Method ${ }^{6}$. The line so defined is called a median regression line and is the practical "best fit" for most data.

\section{6 REFERENCES}

1. National Bureau of Standards, 1954, "Statistical Theory of Extreme Values and Some Practical Applications by Emil J. Gumbel, " A Series of Lectures by Emil J. Gumbel, National Bureau of Standards Applied Mathematics Series, Number 33, National Bureau of Standards, Washington, D.C.

2. "Survey of Practical Applications of Extreme-Value Theory," op. cit., Lecture 1.

3. "Exceedances, Return Periods, and Probability Papers," op. cit., Lecture 2.

4. "Exact and Asymptotic Distributions of Extremes," op. cit., Lecture 3.

5. King, J. R., 1971, Probability Charts for Decision Making, ISBN 0-8311-1023-6

6. Ferre11, E. B., 1958, "Probability Paper for Plotting Experimental Data," Industrial Quality Control, Vol. XV, No. 1 . 